\section{What influences the implementation of interceptive orthodontics in primary care?}

\author{
F. Borrie, ${ }^{* 1}$ D. Bonetti ${ }^{1}$ and D. Bearn ${ }^{1}$
}

IN BRIEF
Questions what it is that influences
the implementation of mixed dentition
interceptive orthodontic treatment in
primary care.
- Reports that lack of knowledge, self-
confidence and experience are the three
main barriers to providing interceptive
orthodontic care.
Finds general dental practitioners' lack of
self-confidence is the greatest barrier to
providing interceptive orthodontic care.

\begin{abstract}
Objective To understand what influences the implementation of mixed dentition interceptive orthodontic treatment in primary care. Methods Postal survey of a random sample of 400 general dental practitioners in Scotland. The questionnaire assessed knowledge, beliefs and attitudes towards providing interceptive treatment in seven different clinical scenarios in order to identify variables that may explain the decision to undertake this treatment. Results One hundred and one (25\%) completed questionnaires were received. Confidence to carry out the treatment plan (16\%), knowledge (11\%), and age (7\%) all significantly predicted intention to provide interceptive treatment. Conclusions The greatest barrier to providing interceptive orthodontic care in general dental practice is practitioners' lack of self-confidence relating to the effectiveness of their chosen treatment plan.
\end{abstract}

\section{BACKGROUND}

Interceptive orthodontics (IO) is a term that includes a range of interventions in the mixed dentition, which aim to prevent or reduce the severity of malocclusion in the permanent dentition. The general dental practitioner (GDP) plays a very important role in the identification and diagnosis of orthodontic problems presenting early. If intercepted and correctly managed during the mixed dentition, many malocclusions may be eliminated or reduced in severity, saving the patient from complex orthodontic treatment at a later stage. ${ }^{1}$

The literature suggests, however, that GDPs are reluctant to implement interceptive orthodontic treatment. ${ }^{2,3}$ Sutton et al. looked at the self-perceived needs of general dental practitioners; ${ }^{2}$ with regard to orthodontics, $11 \%$ perceived themselves to have a good level of knowledge, 59\% thought it to be average and 30\% poor. For those who felt it to be poor:

- Twenty-eight percent of them felt it was due to lack of clinical practice

- Twenty-five percent due to lack of undergraduate training

- Nineteen percent due to lack of postgraduate training

'University of Dundee, Dundee Dental Hospital and School, Park Place, Dundee, DD1 4HR

${ }^{*}$ Correspondence to: Dr Felicity Borrie

Email:f.borrie@dundee.ac.uk

\section{Refereed Paper}

Accepted 17 April 2014

DOI: 10.1038/sj.bdj.2014.525

${ }^{\circ}$ British Dental Journal 2014; 216: 687-691
- Nineteen percent due to lack of interest

- Nine percent due to lack of patient demand or lack of job satisfaction.

Fleming and Dowling found 63\% were satisfied with the academic component of the orthodontic course and 54\% were satisfied with the clinical component. ${ }^{3}$ Curiously, $69 \%$ felt they were competent at orthodontic assessment and 60\% were competent at managing an orthodontic emergency. Both of these were learning outcomes in the General Dental Council (GDC) document, The first five years ${ }^{4}$ which was the current document at that time, and are still included in the recent document, Preparing for practice. ${ }^{5}$ Ninety-six percent felt they were competent at referring appropriately and $76 \%$ felt they had the knowledge to use removable appliances. However, only $24 \%$ would correct an anterior crossbite and 15\% would fit a space maintainer, suggesting that there is a disparity between knowledge and clinical application.

More recently, Jackson et al. surveyed orthodontic referral behaviour of general dentists, demonstrating 52\% of dentists were correct in assessing treatment need, but only $20 \%$ of dentists selected the correct time for referral. ${ }^{6}$ However, there is no real understanding about the barriers or facilitators of the implementation of interceptive orthodontic treatment in primary dental care.

Considering newly qualified dentists' views on their undergraduate course may help to understand current practice in primary care. Derringer has evaluated orthodontic teaching in dental schools across the UK and has found there to be a huge variation in content, length of course (in terms of hours) and in student assessment and examination. ${ }^{7,8}$ Over a decade ago, a study investigated the skills and knowledge vocational dental practitioners acquired as undergraduates in the UK. ${ }^{9}$ Interestingly, only 58\% were satisfied with the theoretical information they received in orthodontics. Only 45\% felt that their practical orthodontic experience had been relevant to their current practice and only 46\% felt that they would be able treat simple cases with removable appliances. Forty percent of respondents felt that their undergraduate course could have been improved by gaining greater practical experience.

Patel et al. compared the views of new vocational dental practitioners (VDPs) and their trainers, regarding how undergraduate dental education prepared them for their vocational training (VT). ${ }^{10}$ They concluded that deficiencies should be targeted during the vocational training year. However, there are likely to be many competing demands during the VT year, and addressing any deficiency is dependent on the trainer having the necessary skills.

In order to better understand the apparent reluctance to undertake IO two established psychological theories, the theory of planned behaviour (TPB) $)^{11,12}$ and social cognitive theory (SCT), ${ }^{13-15}$ widely used in health psychology, may help. The TPB suggests attitudes toward behaviour, peer pressure 
and perception of ability to perform the behaviour shape an individual's intentions and behaviours. The SCT suggests that an individual is more likely to perform a desired behaviour if they are confident (have high self-efficacy) in their ability to perform it. The study by Bonetti et al. uses the TPB in relation to dental decontamination. ${ }^{16}$ It discusses how this theory "predicts an individual is more likely to intend to follow best practice if they intend to do so, and that they are more likely to intend to do so if they believe that they are able to overcome likely barriers, if they think that doing so will results in consequences that they value, and if they believe that other people they respect want them to.' SCT theory has been used in dentistry to further an understanding of the beliefs supporting intention to become a dental vocational trainer. ${ }^{17}$ This study used the predictive measures of attitude towards becoming a trainer, attitude towards attending a trainer course and confidence in the ability to train (training self-efficacy). The psychological model of SCT provided a basis for understanding intention to become a vocational trainer.

The following study uses the TPB and SCT as frameworks to further an understanding of factors that may influence the implementation of IO in primary care.

\section{METHODS}

Data collection was by a postal survey. The development of the questionnaire was informed by a qualitative study of seven GDPs using semi-structured interviews (predictive measures) and expert consensus (outcome scenarios).

\section{Subjects}

The participants in this questionnaire study were GDPs in Scotland. Those who had a patient list with less than 10\% children were excluded from this study as it was felt that they would have insufficient exposure to children requiring interceptive treatment to give valid responses as situations requiring interceptive orthodontics occur in only approximately 15 to $49 \%$ of children. ${ }^{18-20}$

Four hundred GDPs were randomly selected from the Management, Information and Dental Accounting System (MIDAS) database, which is managed by Practitioner Services Division (PSD) of NHS National Services Scotland (NSS). Using a list of random sampling numbers, selected GDPs were sent the questionnaire with instructions on how to complete it.

\section{Scenarios}

Two orthodontists (FB and DB) constructed six picture-based scenarios of common mixed dentition developmental anomalies. The scenarios were:

1. Abnormal eruption sequence, with erupted permanent upper lateral incisors and retained deciduous upper central incisors, presenting in a 9-year-old

2. An anterior crossbite of the upper right permanent central incisor, in a 9-year-old

3. Carious lower first permanent molars, in a 10-year-old, reporting of sensitivity to cold from these teeth

4. An increased overjet, in a 10-year-old male who plays a lot of sport

5. A marked anterior open bite, in a 10-year-old who has a digit sucking habit

6. An infra-occluded lower right second deciduous molar, with fully erupted lower left second premolar, in a 13-year-old female.

One additional scenario (Scenario 7) was included that did not require any active intervention. It presented a 5-year-old in the primary dentition, with an anterior open bite, with no history of digit sucking. Each scenario comprised of a photograph illustrating the malocclusion and two or three sentences describing the condition. Scenario 1 was as follows:

'This 9-year-old presents to your practice for a routine check-up. The upper right central incisor is in cross bite, but the patient is unaware of this.'

\section{Questions}

A range of 22 behaviours were identified as possible responses to each scenario (Table 1). The following questions were asked in relation to these 22 behaviours:

'Which procedures would you carry out in your practice for this patient?'

'Which procedures do you think should ideally be carried out for this patient?'

For each scenario there were then a further six questions, shown in Table 2, related to attitude and self-efficacy, which were answered using a 1 to 10 Likert scale, with $1=$ not at all and $10=$ extremely.

At the end of the questionnaire were a final six questions, shown in Table 3, related to global attitude and self-efficacy, which again were answered using a 1 to 10 Likert scale, with $1=$ not at all and $10=$ extremely. Questionnaires were initially posted on the 4 June 2010, with a reminder questionnaire sent by post on the 25 June 2010, followed by a postcard reminder on the 19 July 2010.

\section{Outcome measure}

A consensus expert opinion was used to

\begin{tabular}{|c|c|}
\hline & Behaviour \\
\hline 1 & Refer to a specialist for treatment \\
\hline 2 & $\begin{array}{l}\text { Refer to a specialist for a treatment plan } \\
\text { for you to carry out the treatment }\end{array}$ \\
\hline 3 & Fit a space maintainer \\
\hline 4 & Take an alginate impression \\
\hline 5 & Take a periapical radiograph \\
\hline 6 & Take an OPT radiograph \\
\hline 7 & Take an upper anterior occlusal radiograph \\
\hline 8 & $\begin{array}{l}\text { Explain to parent and patient the benefits } \\
\text { and risks of providing treatment }\end{array}$ \\
\hline 9 & Check for mobility of a deciduous tooth \\
\hline 10 & Diagnose a digit sucking habit \\
\hline 11 & $\begin{array}{l}\text { Design and fit an upper removable } \\
\text { appliance }\end{array}$ \\
\hline 12 & Restore a deciduous tooth \\
\hline 13 & Restore a permanent tooth \\
\hline 14 & Extract a deciduous tooth \\
\hline 15 & Extract a permanent tooth \\
\hline 16 & Palpate for an unerupted permanent tooth \\
\hline 17 & $\begin{array}{l}\text { Design and fit a digit sucking deterrent } \\
\text { appliance }\end{array}$ \\
\hline 18 & Design and fit a sports mouthguard \\
\hline 19 & Design and fit a functional appliance \\
\hline 20 & $\begin{array}{l}\text { Provide instructions for care of the chosen } \\
\text { appliance }\end{array}$ \\
\hline 21 & Nothing, reassure patient this is normal \\
\hline 2 & $\begin{array}{l}\text { Continue to monitor the developing } \\
\text { permanent dentition }\end{array}$ \\
\hline
\end{tabular}

develop the scoring system for a behaviour intention score. Behaviours selected by the subject that were correct had a single mark allocated. Behaviours that were not correct, but caused no harm, were assigned no marks. Negative marking was used on answers to questions where providing the behaviour would have been harmful to the patient. Lastly, key behaviours were identified for each scenario and additional weighting applied to these. The behaviour intention score was then converted to a percentage.

The outcome measure (dependent variable) was the intention to provide the correct behaviour as measured by the behaviour intention score.

\section{Predictive measures}

Predictive measures (independent variables) were created for each scenario for selfefficacy, attitude and knowledge.

\section{Self-efficacy}

Self-efficacy was assessed in two ways, scenario specific and globally. Scenario 


\section{Table 2 Questions per scenario}

\begin{tabular}{l|l}
$\begin{array}{l}\text { Predictive } \\
\text { measure }\end{array}$ & Question \\
\hline \multirow{3}{*}{ Self-efficacy } & $\begin{array}{l}\text { How confident are you that you have designed an effective treatment plan for this patient? } \\
\text { powient? }\end{array}$ \\
\cline { 2 - 2 } & $\begin{array}{l}\text { How confident are you that the procedures you have ideally chosen for this scenario are } \\
\text { correct? }\end{array}$ \\
\hline \multirow{3}{*}{ Attitude } & $\begin{array}{l}\text { How effective do you think your treatment plan can be in preventing the need for further } \\
\text { orthodontic treatment for this patient? }\end{array}$ \\
\cline { 2 - 2 } & $\begin{array}{l}\text { How important do you think it is to carry out any interceptive orthodontics for this patient } \\
\text { in primary care? }\end{array}$ \\
\cline { 2 - 2 } & $\begin{array}{l}\text { How likely is it that this patient would be worse off if you did not carry out any } \\
\text { interceptive treatment? }\end{array}$ \\
\hline
\end{tabular}

Table 3 Global questions

\begin{tabular}{|c|c|}
\hline $\begin{array}{l}\text { Predictive } \\
\text { measure }\end{array}$ & Question \\
\hline \multirow{3}{*}{ Self-efficacy } & $\begin{array}{l}\text { How confident are you that you can formulate effective interceptive orthodontic treatment } \\
\text { plans for your primary care patients? }\end{array}$ \\
\hline & $\begin{array}{l}\text { How confident are you that you can effectively carry out all the interceptive orthodontic } \\
\text { procedures that are within the scope of primary care? }\end{array}$ \\
\hline & $\begin{array}{l}\text { How confident are you that you can effectively carry out any interceptive orthodontics } \\
\text { with uncooperative children? }\end{array}$ \\
\hline \multirow{3}{*}{ Attitude } & $\begin{array}{l}\text { How effective do you think you can be, with the provision of interceptive orthodontics, in } \\
\text { preventing the need for further orthodontic treatment? }\end{array}$ \\
\hline & $\begin{array}{l}\text { How important do you think it is to carry out any interceptive orthodontics in primary } \\
\text { care? }\end{array}$ \\
\hline & $\begin{array}{l}\text { In general, how likely is it that patients would be worse off if you did not carry out any } \\
\text { interceptive treatment? }\end{array}$ \\
\hline
\end{tabular}

specific self-efficacy focused on the confidence in designing the plan ('selfefficacy design'), confidence in carrying out the plan ('self-efficacy carry out'), and confidence in giving the correct answer ('self-efficacy answers').

These were totalled to give the selfefficacy indirect score.

The global self-efficacy questions (Table 3) were also used as predictive measures ('selfefficacy global design', 'self-efficacy global carry out' and 'self-efficacy uncooperative child'). These were also totalled to give the self-efficacy global score.

\section{Attitude}

Attitude was also assessed in two ways, scenario specific and globally. Scenario specific attitude focused on effectiveness of the chosen plan ('attitude effect') the importance of interceptive orthodontics for this patient ('attitude important') and how likely the patient would be worse off if nothing was done ('attitude risk'). These were totalled to give the attitude indirect score.

The global attitude questions (Table 3) were also used as predictive measures ('attitude global effect', 'attitude global important' and 'attitude global worse off').

\section{Knowledge}

Knowledge was assessed from the question 'Which procedures do you think should ideally be carried out for this patient?' for the 22 behaviours for each scenario. The responses were compared to the consensus expert opinion. A single mark was allocated to each correct response.

\section{Demographics}

Subject gender and age were included as predictive measures.

\section{Sample size}

A power analysis indicated that a minimum sample of 146 GDPs was required to detect a medium effect size of 0.15 in a regression equation with six predictors with alpha $=0.05$, power $=0.95$.

Recent studies with GDPs suggest a wide variety of response rates, from 41 to $83 \%,{ }^{21-25}$ and a $40 \%$ response rate was anticipated. Therefore, it was decided to use a sample of 400 GDPs.

\section{Analysis plan}

Following the return of completed questionnaires, the data was entered into SPSS v 19 (IBM SPSS Statistics for Windows,
Version 19.0, IBM Corp. Released 2010). Data set cleaning was performed, including substituting any missing items with the mean of the measure (if two or fewer items from that measure were missing). Data was examined for normal distribution and no outliers were found.

For each predictive measure Cronbach's alpha was calculated to assess internal reliability. Items were removed from further analysis if they negatively impacted on the Cronbach's alpha.

Relationships between predictive measures and outcome measure were examined using correlation and regression analysis.

\section{Ethical approval}

Advice was sought from the East of Scotland Research Ethics Service before undertaking the study regarding the need for ethical review and they confirmed ethical approval was not necessary for this project.

\section{RESULTS}

A total of 118 questionnaires were returned: 101 completed, 6 where the GDP had either retired or didn't complete it; and 11 marked 'gone away' by Royal Mail.

of the 101 completed questionnaires, one participant completed the entire questionnaire apart from the demographics, but it was decided to still include their responses. From the available data for demographics $(n=100)$ the sample consisted of 66 males and 34 females, with an age range of 24 to 74 years, mean 43.2 years. Ninety-two subjects worked in the general dental services, with seven based in the community services and one in a mixed post. Fifty-two had completed vocational training and 48 had not.

\section{Internal consistency}

The internal reliability analysis results suggested that only three scenarios be retained in the analyses, Scenarios two, five and six. All variables were recalculated to include data from only these three scenarios.

\section{Behavioural intention score}

The results of the correlation analysis are presented in Table 4. Both 'self-efficacy global design', and 'self-efficacy global carry out, resulted in identical values. Consulting the correlation table showed these had a high correlation to each other (high bivariate correlation), therefore only one of these was included in further analysis.

An exploratory stepwise multiple regression analysis was performed inputting the following predictive measures: 'selfefficacy indirect,' 'self-efficacy global,' 'attitude global,' 'knowledge,' and 'age.' The 
adjusted $\mathrm{R}$ square was $0.33(\mathrm{p}<0.0005)$. Significant variables are shown in Table 5.

Following this, the individual predictive measures that made up 'self-efficacy global, and which were significant from the correlation, were input in a second regression. This was to try and identify which particular aspect of global selfefficacy was helping to drive the intention of behaviour. Therefore, 'self-efficacy global carry-out' and 'self-efficacy uncooperative child' were used, along with knowledge and age. From this second regression the results were adjusted R square was 0.34 ( $\mathrm{p}<0.0005)$. Significant variables are shown in Table 6.

The results suggest that three variables: global self-efficacy regarding carrying out the treatment, knowledge, and age account for 34\% of the variance of the behaviour intention score. The self-efficacy component accounts for approximately $16 \%$ of the variance, $11 \%$ knowledge and $7 \%$ age .

\section{DISCUSSION}

The results of this study were in line with theory expectations that confidence is the key factor influencing behaviour. The less confident dentists were the less likely they were to implement IO treatment. The exact reason they lack confidence is not clear from this data. Anecdotal evidence suggests it may be related to a lack of experience in carrying out IO procedures, or a reluctance to carry out procedures on children.

Over the past decade there has been a reduction in the requirement of level of knowledge and skills in the field of orthodontics needed to graduate, as defined by the GDC. ${ }^{4,5}$ Perhaps older dentists are better equipped to deal with these scenarios, gaining experience in dealing with these IO scenarios from an early stage in their careers. This explains the finding of confidence, knowledge and age. Having identified these three variables and explored reasons why they might be driving GDPs decision making, it would appear that they are closely linked.

There was a low Cronbach's alpha for the overall behaviour intention score when all of the scenarios were included, and therefore only three scenarios were used for further data analysis (scenarios two, five and six). The excluded scenarios may have had a degree of ambiguity so that the GDPs did not make consistent decisions. However, the three remaining scenarios covered a range of IO treatments and still provide the breadth of data to draw generalisable conclusions.

In order to have avoided this, more extensive piloting of the questionnaire could have been undertaken to reduce any ambiguity in the scenarios. Another explanation for the lack of internal

\begin{tabular}{|c|c|c|c|c|}
\hline \multirow{2}{*}{$\begin{array}{l}\text { Predictive measures (independent } \\
\text { variables) }\end{array}$} & \multicolumn{3}{|c|}{ Descriptive statistics } & \multirow{2}{*}{$\begin{array}{l}\begin{array}{l}\text { Pearson's } \\
\text { correlation }\end{array} \\
\text { Intention }\end{array}$} \\
\hline & $\begin{array}{l}\text { Cronbach's } \\
\text { Alpha }\end{array}$ & Range & Mean (SD) & \\
\hline Behaviour intention score (\%) & 0.53 & $32.22-96.97$ & $61.84(17.03)$ & 1.00 \\
\hline Self-efficacy indirect & 0.94 & $1-10$ & $7.72(1.59)$ & $0.363^{* *}$ \\
\hline Self-efficacy design & 0.77 & $3-10$ & $7.75(1.58)$ & $0.334^{* *}$ \\
\hline Self-efficacy carry out & 0.73 & $3-10$ & $7.72(1.75)$ & $0.377^{* *}$ \\
\hline Self-efficacy answers & 0.85 & $3-10$ & $7.69(1.66)$ & $0.326^{* *}$ \\
\hline Attitude indirect & 0.80 & $2-10$ & $7.36(1.39)$ & 0.145 NS \\
\hline Attitude effect & 0.56 & $3-10$ & $6.67(1.68)$ & 0.051 NS \\
\hline Attitude important & 0.62 & $1-10$ & $7.73(1.59)$ & $0.224^{*}$ \\
\hline Attitude risk & 0.67 & $3-10$ & $7.68(1.68)$ & 0.097 NS \\
\hline Self-efficacy global & 0.85 & $1-10$ & $5.11(2.13)$ & $0.398^{* *}$ \\
\hline Self-efficacy global design & N/A & $1-10$ & $6.06(2.49)$ & $0.413^{* *}$ \\
\hline Self-efficacy global carry out & N/A & $1-10$ & $6.06(2.49)$ & $0.413^{* *}$ \\
\hline Self-efficacy uncooperative child & N/A & $1-9$ & $3.22(2.14)$ & $0.232^{*}$ \\
\hline Attitude global & 0.79 & $2-10$ & $6.77(1.79)$ & $0.328^{* *}$ \\
\hline Attitude global effect & $\mathrm{N} / \mathrm{A}$ & $1-10$ & $5.93(2.24)$ & $0.295^{* *}$ \\
\hline Attitude global important & N/A & $1-10$ & $7.24(2.22)$ & $0.316^{* *}$ \\
\hline Attitude global worse off & N/A & $2-10$ & 7.14 (1.93) & $0.209^{*}$ \\
\hline Total knowledge & 0.52 & $10-58$ & $41.21(7.44)$ & $0.347^{* *}$ \\
\hline Gender & N/A & $1-2$ & $1.34(0.48)$ & 0.116 \\
\hline Age of participant & N/A & $24-64$ & $43.07(11.01)$ & $0.399^{* *}$ \\
\hline
\end{tabular}

\begin{tabular}{|c|c|c|}
\hline Predictor variable & Beta & $P$ \\
\hline Age & 0.305 & $p<0.001$ \\
\hline Knowledge & 0.348 & $p<0.0005$ \\
\hline Self-efficacy global & 0.269 & $p<0.003$ \\
\hline
\end{tabular}

Table 6 Contribution of each variable to

consistency is GDPs consider IO as discrete individual tasks, with no overriding theme; therefore there is indeed little internal consistency in decision making in this area.

Multiple factors influence behaviour, for example religion and socioeconomic status. These were intentionally not investigated in this questionnaire, as they are not possible to change. In view of this, it was reasonable to have been able to account for up to $34 \%$ of the variance associated with the behaviour intention score.

There was the relatively low response rate in the study. The timing of the postal survey the model

\begin{tabular}{l|l|l}
\multicolumn{2}{l}{ the model } \\
\hline Predictor variable & Beta & $P$ \\
\hline SE global carry out & 0.29 & $p<0.002$ \\
\hline Knowledge & 0.35 & $p<0.0005$ \\
\hline Age & 0.29 & $p<0.001$ \\
\hline
\end{tabular}

overlapped with the start of school holidays, which may have had a negative impact. The list of addresses from MIDAS may not have been as up to date as it could be, explaining why approximately 20\% of the GDPs failed Nevertheless, the sample demographics, in terms of age and gender, match those of GDPs in Scotland ${ }^{26}$ indicating that a representative sample was obtained and therefore the low response rate should not have influenced the generalisability of our results.

This study has successfully furthered an understanding of the implementation of to return the questionnaire having moved. 
IO in primary care. It would appear to be the first identifying barriers to providing IO by general dental practitioners using simulated scenarios. The results indicate that self-efficacy relating to carrying out treatment, knowledge and age are driving GDPs' decision making.

The relationship between knowledge and behaviour intention is complex and often reliant on other factors. ${ }^{27,28}$ Michie et al. have identified 12 domains to explain behaviour change: knowledge; skills; social/ professional role and identity; beliefs about capabilities; beliefs about consequences; motivation and goals; memory, attention and decision process; environmental context and resources; social influences; emotion regulation; behavioural regulation; and nature of the behaviour. ${ }^{29}$ This study did not explore all these varied domains, but was still able to account for 34\% of the variance. Although knowledge accounted for 11\% of the variance it is unlikely that targeting knowledge in an intervention would in itself lead to behaviour change.

The next step therefore is to design an intervention aimed at encouraging GDPs to provide IO in primary care, by increasing their self-efficacy associated with carrying out their treatment plans and improving their knowledge in the field on IO. From the literature it can be seen that designing a complex intervention to change behaviour is difficult. Disseminating printed educational material is ineffective at changing practice and changing behaviour can be challenging. Various psychological theories have been developed to explain behaviour and ways to change behaviour. Self-efficacy seems to play an important role in changing behaviour and can be increased through targeted training involving modelling. There will be the challenge of how to assess the effectiveness of the intervention, particularly as this may not be possible within the constraints of the NHS. This investigation will be a cluster randomised controlled trial testing a range of interventions designed to increase the confidence and knowledge of GDPs surrounding the provision of interceptive orthodontic in primary dental care. It is currently under development.

\section{CONCLUSIONS}

From this research it would appear that:

1. The biggest barrier to providing

interceptive orthodontic care in general dental practice is confidence relating to how effectively the plan can be carried out for the patient and this explains $16 \%$ of the variance

2. Lack of knowledge also acts as a barrier, accounting for a further 11\%, with age (youth) explaining a further 7\%.

Further research is planned to investigate how to improve the provision of interceptive orthodontic care in general dental practice by means of a cluster randomised controlled trial.

We would like to thank the Scottish Dental Practice Based Research Network (SDPBRN) team who supported and funded this study, and the dentists who gave their time to complete the questionnaire.

1. Al Nimri K, Richardson A. Interceptive orthodontics in the real world of community dentistry. Int $J$ Paediatr Dent 2000; 10: 99-108.

2. Sutton F, Ellituv Z N, Seed R. A survey of selfperceived educational needs of general dental practitioners in the Merseyside region. Prim Dent Care 2005; 12: 78-82.

3. Fleming PS, Dowling P A. A survey of undergraduate orthodontic training and orthodontic practices by general dental practitioners. J Ir Dent Assoc 2005: 51: 68-72.

4. Jackson O A, Cunningham S J, Moles D R, Clark $J$ R. Orthodontic referral behaviour of West Sussex dentists. Br Dent J 2009; 207: E18.

5. Derringer K A. Undergraduate orthodontic teaching in UK dental schools. Br Dent J 2005; 199: 224-232.

6. Derringer K A. Undergraduate orthodontic assessment and examination in UK dental schools. Br Dent J 2006; 201: 225-229.

7. Murray F J, Blinkhorn A S, Bulman J. An assessment of the views held by recent graduates on their undergraduate course. Eur J Dent Educ 1999; 3: 3-9.

8. Patel J, Fox K, Grieveson B, Youngson C C. Undergraduate training as preparation for vocational training in England: A survey of vocational dental practitioners' and their trainers' views. Br Dent J 2006; 201: 9-15.

9. Ajzen I. Perceived behavioural control, self-efficacy, locus of control, and the theory of planned behaviour. J App/ Soc Psychol 2002; 32: 665-683.

10. Ajzen I. The theory of planned behaviour. Organizational Behaviour and Human Decision Processes 1991; 50: 179-211.

11. Bandura A. Self-efficacy: toward a unifying theory of behavioural change. Psychol Rev 1977; 84:
191-215.

12. Bandura A. Health promotion by social cognitive means. Health Educ Behav 2004; 31: 143-164.

13. Bandura A, Adams N E. Analysis of self-efficacy theory of behavioural change. Cognitive Ther Res 1977; 1: 287-310.

14. Bonetti D, Young L, Black I, Cassie H, Ramsay C R, Clarkson J. Can't do it, won't do it! Developing a theoretically framed intervention to encourage better decontamination practice in Scottish dental practices. Implement Sci 2009; 4: 31.

15. Bonetti D, Ross J, Stewart S, Clarkson J. What influences intention to become a postgraduate trainer; Br Dent J 2007; 203: 31-35.

16. Ackerman J L, Proffit W R. Preventive and interceptive orthodontics: A strong theory proves weak in practice. Angle Orthod 1980; 50: 75-87.

17. Hiles $A$ M. Is orthodontic screening of 9-year-old school children cost effective? Br Dent J 1985; 159: 41-45.

18. Popovich F, Thompson G W. Evaluation of preventive and interceptive orthodontic treatment between three and eighteen years of age. St.Louis: Mosby Company, 1975.

19. Allen F. Factors influencing the provision of removable partial dentures by dentists in Ireland. $J$ Ir Dent Assoc 2010; 56: 224-229.

20. Cherry W R, Lee J Y, Shugars D A, White Jr R P, Vann Jr W F. Antibiotic use for treating dental infections in children: A survey of dentists' prescribing practices. J Am Dent Assoc 2012; 143: 31-38.

21. Humza Bin Saeed M, Daly B, Newton J T. Knowledge and practice of behavioural management principles among dentists treating adults with learning disabilities. Spec Care Dentist 2012; 32: 190-195.

22. Laud A, Gizani S, Maragkou S, Welbury R, Papagiannoulis L. Child protection training, experience, and personal views of dentists in the prefecture of Attica, Greece. Int J Paediatr Dent 2013; 23: 64-71

23. Singh $B P$, Khan $S A$, Agrawal $N$, Siddharth $R$, Kumar $L$. Current biomedical waste management practices and cross-infection control procedures of dentists in India. Int Dent J 2012; 62: 111-116.

24. General Dental Council. The first five years: $a$ framework for undergraduate dental education. 2nd ed. London: GDC, 2002.

25. General Dental Council. Preparing for practice. London: GDC, 2011. Online article available at http:// www.gdc-uk.org/Newsandpublications/Publications/ Publications/GDC\%20Learning\%200utcomes.pdf (accessed April 2014).

26. NHS Education for Scotland. Dental workforce report: September 2012. NES, 2012. Online report available at http://www.nes.scot.nhs.uk/media/1554871/dentalworkforce-report-2012-final.pdf (accessed June 2014).

27. Bonetti $\mathrm{D}$, Johnston $\mathrm{M}$, Clarkson J E et al. Applying psychological theories to evidence-based clinical practice: Identifying factors predictive of placing preventive fissure sealants. Implement Sci 2010; 5: 25

28. Eccles M, Grimshaw J, Walker A, Johnston M, Pitts N. Changing the behaviour of healthcare professionals: The use of theory in promoting the uptake of research findings. J Clin Epidemio/ 2005; 58: 107-112.

29. Michie $S$, Johnston M, Abraham C, Lawton R, Parker D, Walker A. Making psychological theory useful for implementing evidence based practice: A consensus approach. Qual Saf Health Care 2005; 14: 26-33. 